\title{
Association of Preoperative Platelet-to-Lymphocyte Ratio with Atrial Fibrillation after Coronary Artery Bypass Graft Surgery
}

\author{
Hasan Gungor ${ }^{a} \quad$ Abraham Samuel Babu ${ }^{c}$ Cemil Zencir ${ }^{a} \quad$ Mahmut Akpek $^{a}$ \\ Mithat Selvi $^{a} \quad$ Muhammet Huseyin Erkan $^{\text {b }}$ Selim Durmaz ${ }^{\text {b }}$ \\ Departments of ${ }^{\mathrm{a}}$ Cardiology and ${ }^{\mathrm{b}}$ Cardiovascular Surgery, Adnan Menderes University, Aydin, Turkey; \\ 'Department of Physiotherapy, School of Allied Health Sciences, Manipal University, Manipal, India
}

\section{Key Words}

Platelet-to-lymphocyte ratio · Atrial fibrillation · Coronary artery bypass graft surgery

\begin{abstract}
Objective: The aim of this study was to investigate the association between platelet-to-lymphocyte ratio (PLR) and atrial fibrillation (AF) after coronary artery bypass graft (CABG) surgery. Subjects and Methods: A total of 125 patients were retrospectively analyzed. AF was diagnosed using standard clinical criteria, and PLR was calculated as the ratio of the platelets to lymphocytes, obtained from the blood samples that were taken in the fasting state before CABG surgery. The association of different variables with postoperative $A F$ and PLR was calculated using univariate and multivariate analysis. The receiver operating characteristics curve was used to determine the sensitivity and specificity of PLR and the optimal cutoff value for predicting post-CABG AF. Results: Of the 125 patients, 50 with $A F$ (mean age: $67.0 \pm 9.5$ years, 38 males and 12 females) and 75 patients without AF (mean age: 61.1 \pm 9.1 years, 58 males and 17 females) were identified, and the difference in the mean age was statistically significant $(p=$ $0.01)$. PLR was also significantly higher in those with $A F(152.8$ $\pm 82.2)$ than those without $\operatorname{AF}(118.2 \pm 32.9)(p=0.012)$. Uni-
\end{abstract}

\section{KARGER}

E-Mail karger@karger.com www.karger.com/mpp (c) 2016 S. Karger AG, Basel

\section{Karger}

Open access

This is an Open Access article licensed under the terms of the Creative Commons Attribution-NonCommercial 3.0 Unported license (CC BY-NC) (www.karger.com/OA-license), applicable to the online version of the article only. Distribution permitted for non-commercial purposes only. variate analysis showed that age and PLR were associated with AF after CABG surgery $(p<0.001$ and $p=0.005$, respectively). Using a multivariate logistic regression model with the backward elimination method, age and PLR remained as independent predictors of AF after CABG surgery $(p<0.001$ and $p=0.005$, respectively). PLR levels $>119.3$ predicted postoperative AF with $64 \%$ sensitivity and $56 \%$ specificity (AUC: $0.634, p=0.012)$. Conclusion: In this study, age and PLR level were independent predictors of AF after CABG surgery. Patients with an elevated preoperative PLR were at higher risk of $A F$ after $C A B G$ surgery.

(c) 2016 S. Karger AG, Basel

\section{Introduction}

Platelets are the source of inflammatory mediators and lymphocytes have been shown to regulate the immune response during all progressive stages of atherosclerosis [1]. The presence of increased platelets promotes inflammation, which in turn triggers a cascade of events resulting in the release of neutrophils, monocytes, and lymphocytes to the vessel wall $[2,3]$. Increased platelet and decreased lymphocyte levels in the circulation have been reported to be associated with the poor prognosis in car- 
diovascular disease [4-6]. The platelet-to-lymphocyte ratio (PLR) has been defined as a new biomarker of inflammation and has been found to be better than the neutrophil-to-lymphocyte ratio in predicting inflammation in patients with end-stage renal disease [7].

Atrial fibrillation (AF) is the most common arrhythmia after coronary artery bypass graft (CABG) surgery (prevalence between 25 and 40\%) and is a predictor of complications such as thromboembolism, heart failure, renal insufficiency, morbidity, mortality, and longer hospital stay [8-10]. The presence of this postoperative AF has been known to be due to the contribution of systemic inflammation mediated by various proinflammatory cytokines, such as IL-6, IL-8, and TNF- $\alpha$ [11]. In addition to their role in the inflammatory cascade, these proinflammatory cytokines along with leukocyte count and neutrophil-to-lymphocyte ratio have been reported to be higher in patients with AF after CABG surgery than those without AF [12-14]. However, no data exists regarding the association between PLR (a marker of inflammation) and AF after CABG surgery. Therefore, the aim in this study was to investigate the potential association between PLR and the development of AF after CABG surgery.

\section{Subjects and Methods}

\section{Study Population}

Following approval from the Institutional Ethics Committee of Adnan Menderes University, the postoperative medical data of 125 patients were analyzed from a cohort of 350 patients who had undergone isolated CABG surgery from 2014 to 2015. The exclusion criteria were preoperative AF or any other arrhythmia; previous diagnosis of paroxysmal AF; infections; hyperthyroidism; proinflammatory and autoimmune diseases; the presence of a permanent pacemaker or an implantable cardioverter defibrillator; the use of synthetic hormone preparations, steroids, thiazolidinediones, propylthiouracil, amiodarone, and digitalis before CABG surgery; a hemodynamically unstable condition before CABG surgery; the diagnosis of decompensated congestive heart failure; and patients undergoing concomitant valvular surgery and a second bypass surgery.

Baseline clinical characteristics, type of preoperative treatment, echocardiographic and angiographic findings, and intraoperative and postoperative parameters were obtained from medical records. Complete blood counts, which included total white blood cells, neutrophils, lymphocytes, and platelets, were obtained using an automated blood counter, Mindray BC 6800 (Mindray, China). PLR was calculated as the ratio of platelets $\left(10^{3} / \mathrm{uL}\right)$ to lymphocytes, $\left(10^{3} / \mathrm{uL}\right)$ obtained from the blood samples that were taken in the fasting state.

\section{Operative Technique}

In our center, the patients were operated on with median sternotomy under general anesthesia and cardiopulmonary bypass with aortic and venous cannulations following systemic heparin administration (300 IU/kg). Standard cardiopulmonary bypass circuit and surgical management were used. Antegrade hypothermic and hyperkalemic blood cardioplegia was applied to all patients. Surgery was performed under moderate systemic hypother$\mathrm{mia}\left(30^{\circ} \mathrm{C}\right)$. Cardiopulmonary bypass flow was maintained at $2.2-$ $2.5 \mathrm{~L} / \mathrm{min} / \mathrm{m}^{2}$, mean perfusion pressure was maintained between 50 and $80 \mathrm{~mm} \mathrm{Hg}$, and hematocrit level was maintained at 20-25\% during cardiopulmonary bypass. In our center for coronary bypass operations, the left internal mammary artery was preferred for the arterial graft for left anterior descending artery revascularization, whereas saphenous venous grafts were used for other bypasses. Distal anastomoses were done during the aortic cross clamp period and proximal anastomoses were done on the beating heart onto the ascending aorta using a lateral clamp.

\section{Postoperative Atrial Fibrillation}

AF after CABG surgery was defined as irregular arrhythmia lasting for $\geq 5 \mathrm{~min}$ before hospital discharge. In our center, all patients were monitored in the intensive care unit after surgery with a 5-lead monitoring system using the standard lead II configuration. After discharge from the intensive care unit, patients were followed up 6-8 times daily in the service. Following surgery, if a patient manifested with symptoms of palpitations or an irregular pulse, a 12-lead ECG was performed to diagnose the arrhythmia. Episodes of AF were treated according to clinical routines which included pharmacological interventions with intravenous amiodarone or, if contraindicated, with an oral $\beta$-blocker (metoprolol) and/or with electrical therapies like cardioversion.

\section{Statistical Analysis}

All the data were analyzed using the Statistical Package for Social Sciences (SPSS) for Windows (version 18.0; SPSS Inc., Chicago, IL, USA). Continuous variables were tested for normal distribution using the Kolmogorov-Smirnov test. Continuous data are reported as means and standard deviation or median if not normally distributed, and compared using the Student $t$ test or the Mann-Whitney U test between groups. Categorical variables were summarized as percentages and compared using the $\chi^{2}$ test. The receiver operating characteristics curve was used to determine the sensitivity and specificity of PLR and the optimal cutoff value for predicting postoperative $\mathrm{AF}$ in individuals who had undergone CABG surgery. Univariate analysis was used to calculate the association of different variables with postoperative AF. The variables for which the unadjusted $p$ value was $<0.05$ in the logistic regression model were identified as potential risk markers and included in the full multivariate model. Backward elimination multivariate logistic regression analyses using a likelihood ratio test to eliminate variables were utilized. A 2 -tailed $p$ value $<0.05$ was considered statistically significant.

\section{Results}

Of the 125 patients, 50 with AF (mean age: $67.0 \pm 9.5$ years, 38 males and 12 females) and 75 patients without AF (mean age: $61.1 \pm 9.1$ years, 58 males and 17 females) were identified and the difference in mean age was statistically significant $(p=0.01)$. Other baseline characteris- 
Table 1. Baseline characteristics and preoperative medications

\begin{tabular}{|c|c|c|c|}
\hline & $\begin{array}{l}\text { AF patients } \\
(n=50)\end{array}$ & $\begin{array}{l}\text { Non-AF } \\
\text { patients } \\
(n=75)\end{array}$ & $p$ value \\
\hline Age, years & $67.0 \pm 9.5$ & $61.1 \pm 9.1$ & 0.001 \\
\hline Gender & & & 0.863 \\
\hline Female & $12(24)$ & $17(23)$ & \\
\hline Male & $38(76)$ & $58(77)$ & \\
\hline BMI & $29.4 \pm 5.4$ & $28.4 \pm 4.6$ & 0.280 \\
\hline Gensini score & $67.0 \pm 24.0$ & $71.9 \pm 28.8$ & 0.323 \\
\hline Diagnosis & & & 0.575 \\
\hline Stable angina & $24(48)$ & $32(43)$ & \\
\hline USAP & $10(20)$ & $22(29)$ & \\
\hline Non-STEMI & $6(12)$ & $12(16)$ & \\
\hline STEMI & $10(20)$ & $9(12)$ & \\
\hline Hypertension & $33(66)$ & $44(59)$ & \\
\hline Hyperlipidemia & $9(18)$ & $20(27)$ & 0.409 \\
\hline Diabetes mellitus & $21(42)$ & $31(41)$ & 0.261 \\
\hline Smokers & $26(52)$ & $46(61)$ & 0.941 \\
\hline PAD & $0(0)$ & $3(4)$ & 0.301 \\
\hline COPD & $6(12)$ & $8(11)$ & 0.152 \\
\hline Previous medications & & & 0.937 \\
\hline$\beta$-Blocker & $45(90)$ & $64(85)$ & 0.316 \\
\hline $\mathrm{ACEi}$ & $23(46)$ & $39(52)$ & 0.444 \\
\hline $\mathrm{ARB}$ & $7(14)$ & $12(16)$ & 0.511 \\
\hline $\mathrm{CCB}$ & $8(16)$ & $7(9)$ & 0.760 \\
\hline Clopidogrel & $12(24)$ & $20(27)$ & 0.261 \\
\hline Statin & $34(68)$ & $46(61)$ & 0.738 \\
\hline Fibrate & $2(4)$ & $2(3)$ & 0.447 \\
\hline Nitrate & $26(52)$ & $30(40)$ & 0.678 \\
\hline Furosemide & $5(10)$ & $6(8)$ & 0.186 \\
\hline Spironolactone & $2(4)$ & $3(4)$ & 0.699 \\
\hline ASA & $47(63)$ & $61(81)$ & 1.000 \\
\hline
\end{tabular}

Values are presented as $n(\%)$ or means \pm SD. BMI, body mass index; USAP, unstable angina pectoris; STEMI, ST-elevation myocardial infarction; PAD, peripheral arterial disease; COPD, chronic obstructive pulmonary disease; ACEi, angiotensin-converting enzyme inhibitor; $A R B$, angiotensin receptor blocker; CCB, calcium channel blocker; ASA, acetylsalicylic acid.

Table 3. Intraoperative and postoperative parameters

\begin{tabular}{llll}
\hline & $\begin{array}{l}\text { AF } \\
\text { patients } \\
(n=50)\end{array}$ & $\begin{array}{l}\text { Non-AF } \\
\text { patients } \\
(n=75)\end{array}$ & $\begin{array}{l}p \text { val- } \\
\text { ue }\end{array}$ \\
\hline $\begin{array}{llll}\text { Cardiopulmonary bypass time, } \\
\quad \text { min }\end{array}$ & $97.9 \pm 35.2$ & $92.7 \pm 35.1$ & 0.022 \\
Cross clamp time, min & $53.7 \pm 20.4$ & $52.6 \pm 22.6$ & 0.421 \\
ICU stay length, h & $85.4 \pm 60.7$ & $61.2 \pm 39.2$ & 0.001 \\
Extubation time, h & $20.8 \pm 19.7$ & $16.7 \pm 14.1$ & 0.143 \\
Hospital stay length, day & $16.5 \pm 12.8$ & $11.5 \pm 3.4$ & 0.001 \\
\hline
\end{tabular}

Values are presented as means \pm SD. ICU, intensive care unit.
Med Princ Pract 2017;26:164-168 DOI: $10.1159 / 000453614$
Table 2. Laboratory and echocardiographic parameters of patients

\begin{tabular}{|c|c|c|c|}
\hline & $\begin{array}{l}\text { AF patients } \\
(n=50)\end{array}$ & $\begin{array}{l}\text { Non-AF } \\
\text { patients } \\
(n=75)\end{array}$ & $\begin{array}{l}p \text { val- } \\
\text { ue }\end{array}$ \\
\hline Serum glucose, mg/dl & $133.7 \pm 49.2$ & $128.7 \pm 57.8$ & 0.817 \\
\hline Urea & $42.6 \pm 23.2$ & $37.3 \pm 11.3$ & 0.187 \\
\hline Creatinine & $1.23 \pm 1.39$ & $0.89 \pm 0.26$ & 0.504 \\
\hline Sodium & $136.9 \pm 3.2$ & $137.1 \pm 2.4$ & 0.211 \\
\hline Potassium & $4.3 \pm 0.5$ & $4.2 \pm 0.4$ & 0.601 \\
\hline Calcium & $9.3 \pm 0.5$ & $9.2 \pm 0.6$ & 0.139 \\
\hline Magnesium & $2.2 \pm 0.3$ & $2.2 \pm 0.2$ & 0.508 \\
\hline AST & $28.6 \pm 23.2$ & $32.1 \pm 52.8$ & 0.789 \\
\hline ALT & $24.5 \pm 23.2$ & $25.5 \pm 17.2$ & 0.811 \\
\hline Hemoglobin, g/L & $12.8 \pm 1.6$ & $13.5 \pm 1.7$ & 0.650 \\
\hline Hematocrit & $38.3 \pm 4.6$ & $40.0 \pm 4.7$ & 0.029 \\
\hline Red cell distribution width & $14.6 \pm 1.3$ & $14.2 \pm 1.5$ & 0.050 \\
\hline Mean platelet volume & $8.8 \pm 1.4$ & $8.9 \pm 1.5$ & 0.145 \\
\hline Platelet distribution width & $52.8 \pm 6.3$ & $53.4 \pm 8.6$ & 0.499 \\
\hline Platelets, $/ \mathrm{mm}^{3}$ & $262.1 \pm 74.3$ & $256.1 \pm 65.0$ & 0.645 \\
\hline White blood cells, $10^{3} / \mathrm{uL}$ & $8.3 \pm 2.4$ & $8.7 \pm 2.5$ & 0.634 \\
\hline Neutrophil, $10^{3} / \mathrm{uL}$ & $5.9 \pm 4.4$ & $5.6 \pm 2.0$ & 0.299 \\
\hline Lymphocyte, $10^{3} / \mathrm{uL}$ & $2.0 \pm 0.7$ & $2.3 \pm 0.7$ & 0.730 \\
\hline PLR & $152.8 \pm 82.2$ & $118.2 \pm 32.9$ & 0.012 \\
\hline Triglyceride, mg/dL & $152.7 \pm 73.4$ & $179.9 \pm 114.0$ & 0.012 \\
\hline $\mathrm{LDL}, \mathrm{mg} / \mathrm{dL}$ & $114.3 \pm 27.0$ & $115.2 \pm 57.5$ & 0.406 \\
\hline $\mathrm{HDL}, \mathrm{mg} / \mathrm{dL}$ & $37.5 \pm 9.1$ & $35.6 \pm 9.1$ & 0.927 \\
\hline Total cholesterol, mg/dL & $182.5 \pm 33.7$ & $186.5 \pm 67.2$ & 0.304 \\
\hline LVEF, \% & $52.0 \pm 11.9$ & $51.8 \pm 11.1$ & 0.728 \\
\hline Left atrium diameter, $\mathrm{cm}$ & $3.8 \pm 0.4$ & $3.7 \pm 0.4$ & 0.935 \\
\hline LVESD, cm & $3.7 \pm 0.8$ & $3.7 \pm 0.8$ & 0.092 \\
\hline LVEDD, cm & $6.8 \pm 8.9$ & $5.3 \pm 0.7$ & 0.889 \\
\hline
\end{tabular}

Values are presented as means \pm SD. AST, aspartate aminotransferase; ALT, alanine aminotransferase; LDL, low-density of lipoprotein; HDL, high-density of lipoprotein; LVEF, left ventricular ejection fraction; LVESD, left ventricular end systolic volume; LVEDD, left ventricular end diastolic volume; PLR, platelet-tolymphocyte ratio. tics and preoperative medications did not show a statistically significant difference between the groups (Table 1). PLR $(152.8 \pm 82.2$ vs. $118.2 \pm 32.9, p=0.012)$ was significantly higher in the AF group (Table 2). Cardiopulmonary bypass time $(97.9 \pm 35.2$ vs. $92.7 \pm 35.1 \mathrm{~min}, p=$ $0.022)$, intensive care unit length of stay $(85.4 \pm 60.7$ vs. $61.2 \pm 39.2 \mathrm{~h}, p=0.001)$, and length of hospital stay (16.5 \pm 12.8 vs. $11.5 \pm 3.4$ days, $p=0.001)$ were significantly higher (Table 3 ). In univariate analysis, age (odds ratio [OR]: 1.075; 95\% CI: 1.029-1.123, $p<0.001)$, and PLR 
Table 4. Effects of various variables on postoperative atrial fibrillation in univariate and multivariate logistic regression analyses

\begin{tabular}{|c|c|c|c|c|c|c|}
\hline Variables & Unadjusted OR & $95 \% \mathrm{CI}$ & $p$ value & Adjusted $\mathrm{OR}^{1}$ & $95 \% \mathrm{CI}$ & $p$ value \\
\hline Age & 1.075 & $1.029-1.123$ & 0.001 & 1.078 & $1.030-1.128$ & 0.001 \\
\hline Male sex & 1.077 & $0.463-2.507$ & 0.863 & & & \\
\hline Gensini score & 0.993 & $0.979-1.007$ & 0.323 & & & \\
\hline WBC & 0.924 & $0.796-1.072$ & 0.298 & & & \\
\hline $\mathrm{P} / \mathrm{L}$ ratio & 1.014 & $1.004-1.024$ & 0.005 & 1.014 & $1.004-1.024$ & 0.007 \\
\hline LA diameter & 2.972 & $0.827-10.679$ & 0.095 & & & \\
\hline Cardiopulmonary bypass time & 1.004 & $0.994-1.015$ & 0.418 & & & \\
\hline Cross clamp time & 1.002 & $0.986-1.019$ & 0.774 & & & \\
\hline
\end{tabular}

$\mathrm{OR}$, odds ratio; BMI, body mass index; WBC, white blood cells; P/L, platelet/lymphocyte; LVEF, left ventricular ejection fraction; LA, left atrium. ${ }^{1}$ Adjusted for age, $\mathrm{P} / \mathrm{L}$ ratio, and intensive care unit duration.

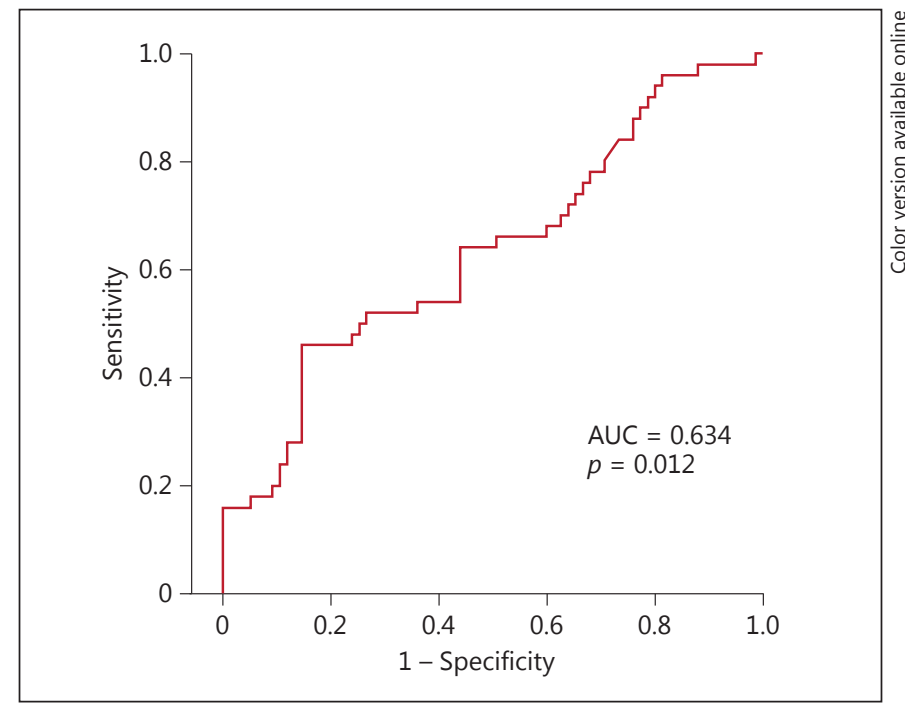

Fig. 1. Receiver operating characteristics curve of the platelet-tolymphocyte ratio for predicting atrial fibrillation after coronary artery bypass graft surgery.

(OR: $1.014 ;$ 95\% CI: $1.004-1.024, p=0.005)$ were associated with AF after CABG surgery. In the multivariate logistic regression model with the backward elimination method, age (OR: 1.078 ; 95\% CI: $1.030-1.128, p<0.001$ ), and PLR (OR: 1.014; 95\% CI: $1.004-1.024, p=0.007$ ) remained as independent predictors of AF after CABG surgery (Table 4). In receiver operating characteristic analysis, PLR levels $>119.3$ predicted postoperative AF with $64 \%$ sensitivity and $56 \%$ specificity (AUC: $0.634, p=$ 0.012) (Fig. 1).

Platelet-to-Lymphocyte Ratio and Atrial Fibrillation

\section{Discussion}

In this study, preoperative PLR was independently associated with AF after CABG surgery and predicted this arrhythmia with $64 \%$ sensitivity and $56 \%$ specificity. These findings are similar to those observed by Saskin et al. [15], in which they not only identified PLR as a risk for postoperative AF, but also for reoperation of sternal dehiscence, occurrence of a neurologic event, prolonged hospital length of stay, and mortality. Similar findings were also reported in our study which identified longer length of both intensive care and hospital stay among those who had AF. However, PLR was not identified as an independent predictor of length of stay.

This study further identified age as an independent predictor of postoperative AF. This could be related to the inflammatory response mediated by advancing age through a variety of molecular mechanisms such as the mitochondrial adaptor protein p66 (Shc) and the family of deacetylase enzymes, the sirtuins [16]. In addition to the normal ageing process, cardiac surgery itself induces a systemic inflammatory response [17]. A previous study reported higher serum resistin levels both in the pre- and postoperative phases along with other proinflammatory markers (IL-6, IL-10, and CRP) [18]. These studies support the finding that inflammatory pathways, from either the advancing age or surgery or even both, could be a potential reason for the development of postoperative AF.

In addition, other mechanisms for postoperative $\mathrm{AF}$ are thought to be due to either atrial or myocardial ischemia, which can affect creatine kinase and contribute to the severe contractile dysfunction and structural and 
electrophysiological remodeling [8-10]. Gary et al. [19] reported that higher platelet volume might change blood viscosity and increase inflammation because PLR was correlated with fibrinogen, which could lead to an increase in blood viscosity and therefore impairment of the tissue oxygen supply. Frustaci et al. [20] demonstrated that the atrial tissues of patients with AF had a higher prevalence of inflammatory infiltrates, fibrosis, and myocyte necrosis than those without AF. Our previous study identified poor coronary collateral circulation preoperatively as a powerful predictor of AF after CABG surgery. Good collateral coronary circulation can affect the occurrence of $A F$ after $C A B G$ surgery by reducing atrial and myocardial ischemia, oxidative damage, inflammation, fibrosis, lipid deposition, and dilatation [21]. Therefore, higher platelet volume may cause atrial and myocardial tissue ischemia by changing blood viscosity and increasing inflammation, thus increasing the risk of AF. However, this is purely speculative as these parameters were not assessed in this study.

The limitations of this study include the relatively small number of patients, its cross-sectional retrospective design, and short follow-up period. ECG monitoring was performed based solely on the findings of physical examination or the complaints of the patient, and the use of telemetry or ambulatory Holter ECG monitoring techniques and asymptomatic or short episodes of AF might have been overlooked.

\section{Conclusion}

In this study, there was an independent association between PLR and AF after CABG surgery. Diagnostic performance of PLR is fair, but it seemed to be a simple method and an indication for an inflammatory marker to predict AF after CABG surgery. Further, prospective trials will be necessary to determine long-term outcomes of AF after CABG surgery with PLR.

\section{Disclosure Statement}

The authors report no conflicts of interest.

\section{References}

1 Smyth SS, McEver RP, Weyrich AS, et al: Platelet functions beyond hemostasis. J Thromb Haemost 2009;7:1759-1766.

2 Henn V, Slupsky JR, Gräfe M, et al: CD40 ligand on activated platelets triggers an inflammatory reaction of endothelial cells. Nature 1998;391:591-594.

3 Langer HF, Gawaz M: Platelet-vessel wall interactions in atherosclerotic disease. Thromb Haemost 2008:99:480-486.

4 Kurtul A, Yarlioglues M, Murat S, et al: Usefulness of the platelet-to-lymphocyte ratio in predicting angiographic reflow after primary percutaneous coronary intervention in patients with acute ST-segment elevation myocardial infarction. Am J Cardiol 2014;114:342-347.

5 Acar G, Kalkan ME, Avci A, et al: The relation of platelet-lymphocyte ratio and coronary collateral circulation in patients with stable angina pectoris and chronic total occlusion. Clin Appl Thromb Hemost 2015;21:462-468.

6 Azab B, Shah N, Akerman M, et al: Value of platelet/lymphocyte ratio as a predictor of allcause mortality after non-ST-elevation myocardial infarction. J Thromb Thrombolysis 2012;34:326-334

7 Turkmen K, Erdur FM, Ozcicek F, et al: Platelet-to-lymphocyte ratio better predicts inflammation than neutrophil-to-lymphocyte ratio in end-stage renal disease patients. Hemodial Int 2013;17:391-396.
8 Mathew JP, Fontes ML, Tudor IC, et al: A multicenter risk index for atrial fibrillation after cardiac surgery. JAMA 2004;291:17201729.

9 Maisel WH, Rawn JD, Stevenson WG: Atrial fibrillation after cardiac surgery. Ann Intern Med 2001;135:1061-1073.

10 Magee MJ, Herbert MA, Dewey TM, et al: Atrial fibrillation after coronary artery bypass grafting surgery: development of a predictive risk algorithm. Ann Thorac Surg 2007; 83:1707-1712.

11 Anselmi A, Possati G, Gaudino M: Postoperative inflammatory reaction and atrial fibrillation: simple correlation or causation? Ann Thorac Surg 2009;88:326-333.

12 Gungor H, Ayik MF, Kirilmaz B, et al: Serum resistin level: as a predictor of atrial fibrillation after coronary artery bypass graft surgery. Coron Artery Dis 2011;22:484-490.

13 Lo B, Fijnheer R, Nierich AP, et al: C-reactive protein is a risk indicator for atrial fibrillation after myocardial revascularization. Ann Thorac Surg 2005;79:1530-1535.

14 Kawahito K, Kobayashi E, Ohmori M, et al: Enhanced responsiveness of circulatory neutrophils after cardiopulmonary bypass: increased aggregability and superoxide producing capacity. Artif Organs 2000;24:37-42.
15 Şaşkın H, Düzyol Ç, Özcan KS, et al: Preoperative platelet to lymphocyte ratio is associated with early morbidity and mortality after coronary artery bypass grafting. Heart Surg Forum 2015; 18:E255-E262.

16 Camici GG, Savarese G, Akhmedov A, et al: Molecular mechanism of endothelial and vascular aging: implications for cardiovascular disease. Eur Heart J 2015;36:3392-3403.

17 Ayaz L, Unlu A, Sucu N, et al: The role of neopterin, C-reactive protein and myeloperoxidase in patients undergoing cardiopulmonary bypass. Med Princ Pract 2010;19:479-484.

18 Canbaz S, Erbas H, Huseyin S, et al: The role of inflammation in atrial fibrillation following open heart surgery. J Int Med Res 2008;36: 1070-1076.

19 Gary T, Pichler M, Belaj K, et al: Platelet-tolymphocyte ratio: a novel marker for critical limb ischemia in peripheral arterial occlusive disease patients. PLoS One 2013;8:e67688.

20 Frustaci A, Chimenti C, Bellocci F, et al: Histological substrate of atrial biopsies in patients with lone atrial fibrillation. Circulation 1997;96:1180-1184.

21 Gungor H, Eryilmaz U, Akgullu C, et al: Preoperative poor coronary collateral circulation can predict the development of atrial fibrillation after coronary artery bypass graft surgery. Coron Artery Dis 2013;24:572-576. 